\title{
UM DESCUIDO
}

\section{Demétrio Panarotto UFSC}

RESUMO: A cidade, nas suas mais variadas possibilidades e diálogos, é por onde se movimentam os poemas de El descuido, de Silvio Mattoni. 0 diálogo aqui proposto se dá a partir do jogo teórico ficcional de uma das narrativas do escritor português, contemporâneo de Mattoni, Gonçalo Tavares; a ele se une algumas questões levantadas pela crítica argentina Beatriz Sarlo, uma leitora benjaminiana das cidades, e os teóricos franceses Michel Foucault, com a ideia do "cuidar de si", e Gilles Deleuze, com a de um "devir".

PALAVRAS-CHAVE: Poesia. Descuido. Cuidar de si. Devir. Cidade.

\section{CARELESSNESS}

ABSTRACT: The poems of El descuido, by Silvio Mattoni, take place in the city, in its diverse possibilities and dialogues. This essay will establish a theoretical-fictional dialogue between Mattoni's poems and the narratives of the Portuguese writer Gonçalo Tavares — an author contemporary to Mattoni. In addition, questions raised by Argentinean critic Beatriz Sarlo (who understands the city in a Walter Benjamin's perspective), and also by the French theoreticians Michel Foucault (with the concept of "care of the self") and Gilles Deleuze (with the concept of "becoming") will enter this dialogue.

KEYWORDS: Poetry. Carelessness. Care of the self. Becoming. City.

Demétrio Panarotto é doutor em Literatura pela Universidade Federal de Santa Catarina. 


\section{UM DESCUIDO}

\section{Demétrio Panarotto}

...locos y chicos no se parecen tanto como los perros y nosotros.

Silvio Mattoni

Gonçalo Tavares nos diz, em um dos livros da coleção O Bairro, O Senhor Breton $^{1}$, que existem dois tipos de palavras, as que trabalham e as preguiçosas. As palavras preguiçosas, para Gonçalo (ou para O Senhor Breton se o leitor preferir), são aquelas que não se movem - são as palavras do excesso de informação, surradas e consumidas diariamente em seu estado embrutecido -, e que acrescentam um grave problema ao texto (ao verso), pois além de não se moverem, fazem com que o leitor não se mova, permaneça inerte. $A$ palavra que trabalha, o verso que trabalha, de outro modo, é aquele que faz com que o leitor se movimente; faz com que o leitor se desloque de seu ponto de inanição, pois delira o verbo deslocando o seu sentido habitual.

Inicio o olhar para El descuido, de Silvio Mattoni, a partir da prosa de Gonçalo Tavares, por considerar que o verso do poeta argentino se encontra neste local em que a palavra que o constitui faz com que o leitor ainda se mova, não o deixa inerte, o tira de seu lugar comum. Há um jogo proposto pelo autor na procura do (de um) leitor. As palavras que compõem os versos não são preguiçosas, estão ali também como provocação, para que o leitor se sinta sacudido por elas, possa se movimentar junto com as várias outras imagens que elas constroem.

O olhar que Mattoni movimenta estende-se, dentre tantos lugares, à cidade, à praça, à estação, ao shopping, ao vizinho, às compras. O descuido é aquilo que dá a possibilidade de se movimentar pelos espaços montados por Mattoni. ${ }^{2}$ Neste ensaio, pretendo, pois, perceber os diálogos possíveis motiva-

${ }^{1}$ TAVARES, Gonçalo Manuel. O senhor Breton e a entrevista. Rio de janeiro: Casa da Palavra, 2009.

2 El descuido é um livro de 2007, editado pela Ediciones Recovecos, Córdoba, Argentina. Silvio Mattoni é, ainda, autor de: El bizantino. Córdoba: Alción, 1994; Trabajos de amor perdidos. Buenos Aires: Último Reino, 1992; Tres poemas dramáticos. Córdoba: Alción, 1995; Sagita- 
dos a partir dos poemas de Mattoni.

Silvio Mattoni nos diz, em "La plaza", segundo poema de El descuido:

\author{
Yo me expongo \\ al deseo insensato de escaparme \\ o a convertir la vida, esto que pasa, \\ en simple material para un poema. ${ }^{3}$
}

No poema, vemos que a praça também é o local do descuido. Do descuido que temos para com o outro. Do descuido do outro para conosco. Do descuido que temos para com nós mesmos. É no descuido que emerge aquilo que não esperávamos. É com ele que emerge algo que insensatamente podemos transformar em material para um poema. Tudo é matéria de poesia, mas nem tudo se converte em um poema. No descuido as palavras trabalham e o leitor se move.

O descuido é para Mattoni, ainda, no primeiro poema do livro, "La cosa perdida", esquecimento. "La escondí demasiado bien." ${ }^{4} \mathrm{O}$ esquecimento brinca com a memória: o que se oferece e o que se esconde. Junto com a recordação de algo, há a outra parte que não se mostra, que permanece escondida. O descuido é, neste outro poema, aquilo que distancia e, ao mesmo tempo, aquilo que aproxima das coisas. Este jogo, entre aquilo que se mostra e aquilo que se esconde, é muito sutil e também faz com que as palavras se movimentem para que possamos percebê-lo.

Foucault nos fala, em $A$ Hermenêutica do Sujeito ${ }^{5}$ - lendo um período longo da antiguidade que vai de Platão ao cristianismo — , da escrita de si, de um cuidar de si, de um converter a si, de um volver o olhar para si, que sugere

rio, Córdoba: Alción, 1998; Koré. Rosario: Beatriz Viterbo, 2000; Canéforas. Buenos Aires: Siesta, 2000; El país de las larvas. Buenos Aires: Paradiso, 2001; Hilos. Córdoba: Alción, 2002; El cuenco de plata. Literatura, poesía, mundo. Buenos Aires: Interzona, 2003; Poemas sentimentales. Buenos Aires: Siesta, 2005; Excursiones. Córdoba: Alción editora, 2006. La división del día. Poemas 1992-2000. Buenos Aires: Mansalva, 2008; La chica del volcán. Córdoba: Alción, 2010; Bataille, una introducción, Buenos Aires: Quadrata, 2011; La canción de los héroes. Santa Fe: Universidad Nacional del Litoral, 2012; Avenida de Mayo. Córdoba: Editorial Nudista, 2012; Peluquería masculina. Bahía Blanca: Vox, 2013. É também tradutor para o espanhol de Francis Ponge, Gilles Deleuze, Michel Foucault, Paul Valéry, Cesare Pavese, Giorgio Agamben, Marguerite Duras, Denis Diderot, Catulo e Henri Michaux, entre outros.

${ }^{3}$ MATTONI, Silvio. La plaza. In: El descuido. Córdoba: Ediciones Recovecos, 2007, p. 11.

${ }^{4}$ Idem. La cosa perdida. In: El descuido, op. cit., p. 09.

${ }^{5}$ FOCAULT, Michel. A Hermenêutica do Sujeito. Trad. Márcio Alves da Fonseca; Salma Tannus Muchail. São Paulo: Martins Fontes, 2004. 
que o leitor deve desviar o olhar dos outros, ou das coisas do mundo, e de voltar o olhar para um tipo de conhecimento que se encontra na relação consigo. Esta ideia, em algum momento, e nos diz Foucault, é uma reconstituição a partir do manuscrito. A escrita de si se inicia pelos rascunhos manuscritos que se tornaram cartas, ou textos, que podem chegar, em algum momento, a serem livros enviados a amigos desconhecidos, como nos diz Peter Sloterdijk, recuperando o escritor Jean Paul, na abertura de sua conferência, Regras para o parque humano ${ }^{6}$. Há um amigo que se ganha através de um livro. Este amigo é um leitor; um leitor de hoje ou um de amanhã. Assim, o livro está próximo daquilo que se cuida, mas também, do descuido.

Desviar o olhar do outro é desviar o olhar da curiosidade. O descuido, de Mattoni não tem a ver com o não cuidar, mas com a imprevisibilidade, com aquilo que nos coloca diante de algo que foge ao esperado. A escrita de Mattoni é, em algum momento - e a capa nos ajuda a entender isso pois o autor traz para o livro a presença das filhas, como se o olhar que nutre pelo outro também passasse pelo exercício da vivência familiar, uma escrita de si, um cuidar de si, próximo daquilo que nos cerca e que nos dá uma pretensa segurança. A escrita de Mattoni também é alimentada pelos descuidos que faz com que nos percamos pelas cidades e nos aproximemos da imprevisibilidade.

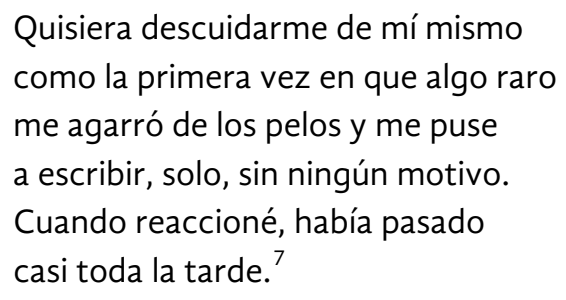

O descuido de si mesmo alimenta um outro tipo de cuidado. Em algum momento fazemos esforços para nos livrar da previsibilidade do que nos cerca e de como a aceitamos passivamente. Nesse sentido, é na tarde que o escritor se descuida do que lhe cerca e, por isso mesmo, por um descuido, um "lapso", escreve o poema acima, "El primer discurso". Este gesto dialoga com o de Kafka, que, em um descuido (que considero) parecido - relatado em seu diário - , numa madrugada ininterrupta, em que teve dificuldades de tirar as

\footnotetext{
${ }^{6}$ SLOTERDIJK, Peter. Regras para o parque humano. Uma resposta à carta de Heidegger sobre o humanismo. Trad. José Oscar de Almeida Marques. São Paulo: Estação Liberdade, 1999.

${ }^{7}$ Idem. El primer discurso. In: El descuido, op. cit., p. 45.
} 
pernas debaixo da escrivaninha quando da chegada da empregada pela manhã, escreveu $O$ veredicto. Por mais que os arredores clamem por atenção, este é o momento em que o descuido se distancia da curiosidade em relação aquilo que nos rodeia, naquilo que nos chama a atenção por estar próximo; todavia, se relaciona, contraditoriamente, com o volver a si do qual nos fala Foucault: parece um descuido consigo mesmo o que alimenta um cuidar de si.

Em "Boulevard", a situação parece que se repete quando na abertura do poema, Mattoni diz:

\section{Camino, no conozco la ciudad y voy buscando um punto de referencia para perderme, pero no del todo. ${ }^{8}$}

Os bulevares nos inserem na cidade. A cidade é o texto para o qual buscamos referências para nos perdermos em parte. É o local em que os descuidos alimentam um jogo entre aquilo que podemos e ao mesmo tempo não conseguimos tocar. É um bosque no qual nos movimentamos, nos extraviamos, mas que em algum momento buscamos o ponto de "uma aparente segurança da saída" para podermos nos perder em outros bosques que alimentam o jogo da escrita e da leitura, das amizades. Daquilo que nos mantém.

Ao ler os poemas de Mattoni, de El descuido, ainda, pareceu-me inevitável o gesto de recuperar com pequenas constatações o livro de Beatriz Sarlo, Cenas da Vida Pós-moderna: intelectuais, arte e vídeo-cultura na Argentina, pela temática que aborda, em especial, quando os poemas tratam de lugares como Shoppings e Bulevares, temas recorrentes em Sarlo. Aponto-as:

A primeira delas é a de que tanto Sarlo como Mattoni são leitores de Baudelaire; Sarlo, com um filtro benjaminiano, monta as suas "cenas" como ponto de partida para trabalhar uma questão teórica de ordem dialética (e talvez este seja o ponto em que o filtro se torne evidente), enquanto que em Mattoni, por sua vez, Baudelaire e o próprio Benjamim ${ }^{9}$, aparecem crus, de modo que as interferências criam um outro tipo de curto-circuito, num sentido mais próximo de Deleuze, de um devir. ${ }^{10}$

\footnotetext{
${ }^{8}$ Idem. Boulevard. In: El descuido, op. cit., p. 19.

${ }^{9}$ BENJAMIN, Walter. Obras escolhidas I. Magia e Técnica, Arte e Política. Trad. Sérgio Paulo Rouanet. 7. ed. São Paulo: Brasiliense, 1994.

${ }^{10}$ Deleuze nos diz em A Literatura e a Vida, texto presente em Crítica e Clínica: "Devir não é atingir uma forma (identificação, imitação, Mimese), mas encontrar a zona de vizinhança,
} 
A segunda delas é que Sarlo nos diz que as culturas se encontram devidamente contaminadas - há um peso nesta avaliação - e exemplifica através de pequenas cenas, é como se as passagens que Benjamin ${ }^{11} \mathrm{faz}$ percorrendo um espaço percebido por Baudelaire, não fizessem mais sentido. Em Mattoni, com um outro olhar, existe uma procura por mover-se dentro destes espaços que Sarlo considera "contaminados", numa busca por pontos de respiro diante dos engessamentos. Este mover-se de Mattoni se faz, recuperando Gonçalo, com palavras que se movem no espaço do verso. Não necessariamente busca saídas, mas ao mesmo tempo não se deixa consumir por isso que parece inevitável, oriundo de uma sociedade (pós-revolução industrial) que se diferencia da anterior por se considerar civilizada.

Sarlo, nos dois momentos, parece dividir os espaços em um jogo dicotômico entre aquilo que nas cidades consideramos os centros antigos de encontro das pessoas, naturalmente localizados no miolo central das cidades, e, no outro lado da moeda, os locais de encontros contemporâneos marcados por estas cápsulas, os shoppings, que são colocados como naves nas cidades e reconfiguram o modo de convívio das pessoas. Há, nos dois espaços, uma série de códigos que definem como e de que modo se deve se portar. Em Mattoni, por sua vez, os dois fazem parte da cidade, e parece inevitável que transitemos nestes espaços, e entre estes espaços, e que junto nos posicionemos criticamente por fazermos parte deles. A questão talvez seja como nos portar diante daquilo que é inevitável, que não temos como resistir, não porque é irresistível, mas porque somos levados a não resistir. De que maneira se pode quebrar este confinamento e esta condição pastoral do andar medido, de um curral para o outro?

O poema abaixo, "Shopping", do mesmo livro aqui trabalhado, nos ajuda a entender como Mattoni parece estar "entre" ou "no meio":

\footnotetext{
¿En dónde

estamos? Un shopping, un mundo de ojos

que miran hacia adentro. Es ideal

para invitar a que mi hijita pregunte
}

\footnotetext{
de indiscernibilidade ou de indiferenciação..." DELEUZE, Gilles. A Literatura e a Vida. In: Crítica e Clínica. Trad. Peter Pál Pelbart. São Paulo: Editora 34, 1997, p. 11.

${ }^{11}$ BENJAMIN, Walter. Obras escolhidas III. Charles Baudelaire, um lírico no auge do capitalismo. Trad. José M. Barbosa e Hemerson A. Baptista. 3. ed. São Paulo: Brasiliense, 1994.
} 
cuánto dinero tengo y cuánto falta y cuánto objeto inútil puedo llegar a concederle. ${ }^{12}$

A cidade que se modifica hoje e que ganha novas impressões é a mesma que se modificava durante os primórdios do século XIX e ganhava as ditas impressões modernas. As galerias, os bulevares, os cafés do século francês, que emergem dos textos de Baudelaire e de Benjamim ${ }^{13}$, e que mudaram a aparência das cidades, nada mais eram do que a tentativa de se livrar de uma parte dos signos que alimentavam as cidades ainda com cara de medievais. Raymond Williams, em $O$ Campo e a Cidade na História da Literatura $^{14}$, nos apresenta uma belíssima leitura destas mudanças. Mudanças que foram sentidas e externadas pelo escritor português Eça de Queiroz, que, em A Cidade e as Serras ${ }^{15}$, reconfigura o seu olhar em relação à cidade luz. Se antes Paris era o centro e a referência do mundo para aquele momento - inclusive para o Eça dos primeiros romances, O Crime do Padre Amaro, O Primo Basílio e Os Maias - aquilo que a fazia tão importante parece perder o charme para Jacinto, o personagem do romance. Lembrando que este desapontamento de Eça - revelado através de Jacinto em uma de suas narrativas - se encontra também em sua opinião crítica exposta nos periódicos (inclusive nos brasileiros) da época.

Euclides da Cunha, em Os Sertões ${ }^{16}$, no início do século XX, nos dizia que estávamos condenados à civilização. Talvez não imaginasse que a palavra civilização também passou a ser um código cifrado pelo qual continua passando pretensas novas ideias com os mesmos antigos interesses. Com novos recursos técnicos e tecnológicos continuamos caminhando pelos espaços que as cidades nos oferecem e junto com os monstros que ela carrega e que nós carregamos. Essa procura, de Mattoni, por se mover neste espaço dito "civilizado" dialoga com Agamben, quando este nos fala que a poesia é o que ainda pode nos salvar, como se a procura por esses respiros seja o que ainda nos mantenha vivos. O fato de nos mantermos vivos em nada sugere que comun-

\footnotetext{
12 MATTONI, Silvio. Shopping. In: El descuido, op. cit., p. 81.

${ }^{13}$ BENJAMIN, Walter. Obras escolhidas II. Rua de mão única. Trad. Rubens Rodrigues Torres Fo e José Carlos Martins Barbosa. 5. ed. São Paulo: Brasiliense, 1995.

${ }^{14}$ WILLIAMS, Raymond. O Campo e a Cidade na História e na Literatura. Trad. Paulo Henrique Britto. São Paulo: Companhia das Letras, 1989.

${ }^{15}$ QUEIROZ, Eça de. A cidade e as serras. Porto Alegre: L\&PM Editores, 1998.

${ }^{16}$ CUNHA, Euclides da. Os Sertões. São Paulo: Editora Nova Cultural, 2002.
} 
gamos com o que nos rodeia, mas que parece imprescindível procurarmos, com Deleuze, essas zonas de vizinhança, de indiscernibilidade ou de indiferenciação. Afinal, o shopping em algum momento é o lugar do controle, daquilo que é vigiado. Naturalmente não são todos que conseguem caminhar por este espaço do mesmo jeito, e dos que caminham, a sensação de estar sendo vigiado é a que sobrevive. No entanto, os centros antigos e as praças também não passam por este excesso de vigia? E o lugar em que moramos? Será que não está se reproduzindo um modelo de controle muito parecido com aquele praticado pelo nazismo, todavia sem a figura de Hitler? Um hitlerismo sem Hitler?

As cidades de hoje, como ocorreu a partir do século XIX, são em toda a sua estrutura aliadas do capital. As cidades continuam se "modernizando", e estas mudanças são, e isso não é novidade alguma, ditadas pelo mundo capitalizado. Muito mais voraz? Sem dúvida. Se o capital continua sendo a mola propulsora que alimenta as cidades, da vida moderna à contemporânea, um dos poemas ganha no título a devida atenção, "El capital":

\section{Se alejaban en el horizonte del consumo los jeans deseados, los clubes, otras cosas que sólo importam porque faltan. ${ }^{17}$}

Em algum momento da história ser moderno era ser contemporâneo. Ser contemporâneo hoje passa naturalmente por outros lugares. No entanto, o capital continua mediando as relações. O limite entre o excesso e a falta é muito tênue. Como se colocar diante sem remediar diante do capital? Assim, a relação de Mattoni com a cidade não parece necessariamente de estranhamento, nem de reconforto, mas de entendimento de como as mudanças ocorrem e como é preciso buscar um espaço para não se acomodar diante delas. Talvez se possa dizer que aquilo que é cotidiano em Mattoni também passa a ser incorporado à produção ficcional em versos de um olhar atento. $E$ os descuidos são um modo de manter o corpo vivo.

Além dos poemas citados e das ainda insipientes abordagens, o livro deste cordobês, que saiu pela Ediciones Recovecos, Córdoba, 2007, nos brinda com outros poemas que valem a menção: "El poema infinito" e "El poema terminado". Neste último, há uma outra questão que nos chama a atenção (recor-

\footnotetext{
${ }^{17}$ Idem. El capital. In: El descuido, op. cit., p. 37.
} 
rente também em outros poemas), que é a quantidade de interrogações que cortam a maioria dos escritos, mesmo quando estas dúvidas sugerem uma aparente apropriação. Portanto, fecho com um trecho deste poema:

\author{
...¿Hasta cuándo, decime, \\ abusarás de nuestra paciencia y vas \\ a repetir lo mismo? Aunque no hay nadie \\ que responda perguntas si no habla \\ y todavia tengo que callarme. Yo \\ no soy el niño cruel o atormentado \\ que no quería nada. Ahora quiero \\ escuchar el reverso del recuerdo, \\ um pozo oscuro en que termina todo. ${ }^{18}$
}

${ }^{18}$ Idem. El poema terminado. In: El descuido, op. cit., p. 33. 